\title{
Methodology for managing environmental innovation projects at the enterprise
}

\author{
Boris Lyamin ${ }^{1, *}$ and Anna Chernikova ${ }^{1}$ \\ ${ }^{1}$ Peter the Great St. Petersburg Polytechnic University, 195251 St. Petersburg, Russia
}

\begin{abstract}
This article provides an in-depth study of methods and approaches to the management of environmental innovation projects developed by domestic and foreign scientists. As a result of the analysis of methods and approaches, it was revealed that they do not take into account the importance of influencing factors on an innovative project, while this does not detail management activities at all stages of the life cycle of an innovative project. A methodology for managing environmental innovation projects was developed. The technique allows you to form a sequence of actions for the subjects of management at the enterprise in order to select the most effective projects that contribute to the achievement of the strategic goals of the enterprise, taking into account the influence of external and internal factors.
\end{abstract}

\section{Introduction}

At the present stage of economic development, organizations need to systematically improve all areas of activity in order to achieve sustainable development. An especially important aspect is to increase the efficiency of production activities: new technologies, materials, techniques appear that can significantly increase production efficiency, at the same time, this may entail not only the expected positive externalities, but also negative ones, such as a reduction in jobs or an increase in the environmental burden. on the habitat. According to the national goals of sustainable development, it is necessary not only to increase the introduction of innovative developments in the real sector of the economy, but at the same time to ensure the transition to rational patterns of consumption and production. This suggests that it is necessary to actively introduce environmental innovations along with technological, organizational, and marketing innovations. Despite the fact that the introduction of innovations can significantly increase the competitiveness of organizations, there is no growth in the number of organizations introducing innovations.

On the contrary, over the past decade, the share of organizations implementing new projects has been decreasing, especially the downtrend has affected environmental innovations (falling from $5.7 \%$ in 2011 to $0.6 \%$ in 2018). It should be noted that the decision to implement an innovative project is influenced by many factors, both internal and external, respectively, the difficult economic situation in Russia has undoubtedly influenced the dynamics of organizations introducing innovative developments. At the same time, increased competition as a result of a decrease in the effective demand of the

${ }^{*}$ Corresponding author: lyamin.bm@gmail.com 
population pushes organizations to implement not only technological innovations, but also environmental innovations.

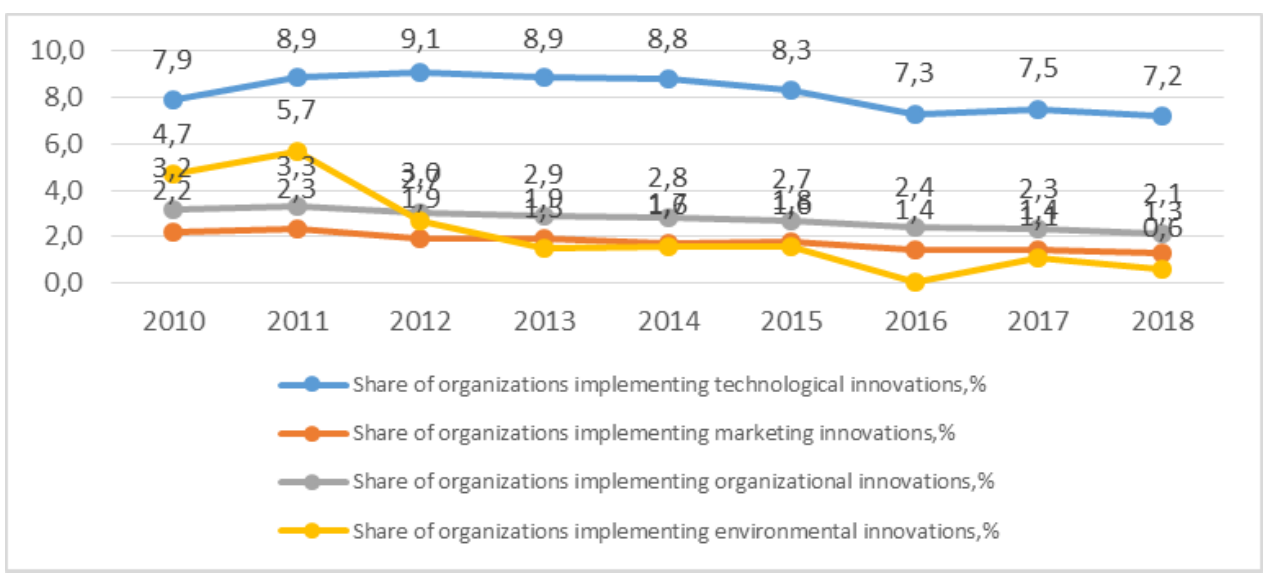

Fig. 1. Share of organizations implementing innovations for the period 2010-2018, by type of innovation. Note: data for 2016 on environmental innovations not provided.

Thus, having considered the quantitative indicators of the introduction of innovations in the real sector of the economy, it can be concluded that, given the current trend in the introduction of innovations, it will be quite problematic to increase the competitiveness of domestic organizations and their products in the world market. The current situation can be corrected by a systematic approach to the support of organizations introducing innovations from the state, as well as effective management of the organization in the implementation of innovative developments. In this regard, there is a need for methodological provision of organizations with tools for effective management of innovative projects

One of the ways to improve the efficiency of business processes in an enterprise is the introduction of various management systems based on the ISO 9000 and 14000 series $[1,2]$. However, when it comes to a particular plant and the application of standards to improve efficiency and quality, the sheer number of choices becomes a challenge. In addition, there is a lot of controversy surrounding the application of the ISO 14000 series standards. Despite the obvious benefits for the company associated with a stable positive correlation between high environmental efficiency, profitability and general well-being, there are concerns on the part of senior management that a rather costly financial and resource mechanism, both at the stage of implementation and during operation, will not provide the necessary result. However, the tightening of environmental legislation is pushing companies to be more attentive to the environment, to improve the safety of production, etc., for example, the main directions that ensure an increase in environmental safety in the production of goods, works, services are:

- Reduction of material costs for the production of a unit of goods, works, services;

- Reducing energy consumption for the production of a unit of goods, works, services;

- Reducing emissions of carbon dioxide (CO2) into the atmosphere;

- Replacement of raw materials and materials with safe or less hazardous ones:

- Reduction of environmental pollution (atmospheric air, land, water resources, noise reduction);

- Implementation of secondary processing (recycling) of production waste, water or materials;

- Conservation and reproduction of natural resources used by agriculture.

Thus, when implementing innovative projects at an enterprise, it is necessary to take into account not only profit in the short and medium term, but also take into account 
environmental risks, since a possible negative impact on the environment from the implementation of an innovative project can lead to not only financial, but also image losses. Based on the indicated problems, it is necessary to consider the existing approaches to the management of innovative projects, taking into account environmental risks.

\section{Materials and Methods}

The development of methodological approaches to the implementation of innovative projects in an organization is relevant both for domestic scientists and for foreign ones. In this regard, it is necessary to consider the existing methods of managing environmental innovation projects at the enterprise. Rogovoy A.A. in his research highlights the effects of the implementation of an innovative project:

- the market efficiency of the innovation process, which determines the degree of conformity of the consumer characteristics of innovative products to the demands of the final sales markets;

- the economic efficiency of the innovation process, which determines the degree of the ratio of costs incurred during the implementation of this process and the results obtained;

- the temporary effectiveness of the innovation process, which characterizes the ability to produce innovations within the framework of the innovation process on time. [3]

The author classifies the effects of the implementation of an innovative project, dividing them into:

- economic;

- social;

- scientific and technical;

- ecological.

At the same time, the effect of the introduction of innovative projects at the micro level also allows obtaining positive effects both at the meso- and at the macro-level: social effect (stabilization and improvement of the situation on the labor market), economic effect (increasing the efficiency of economic activity, labor productivity; ensuring large volumes of tax revenues), innovation effect (providing the region or the country as a whole with leadership in the field of innovation). The whole set of effects leads to a synergistic effect from the implementation of an innovative project. [3]

Pavlova E.I. considers the problem of assessing environmental innovation projects at the state level. [4] To select projects that make the greatest contribution to the sustainable development of the economy, it is proposed to use the indicator of the innovative level of the project (ISPI). The more its value, the more preferable the project. The indicator includes three components - economic (x), environmental (y) and social (z). In this case, Y, $\mathrm{Z}$ is the effect in comparison with the previously used technology,\%. AIMP is a threedimensional quantity, the components of which can be represented as the coordinates of a vector, the origin of which is at the point $(0 ; 0 ; 0)$ (Fig. 2)

The choice of the normal vector is explained by the equivalence of the three components. In practice, the projection vector is determined by the position of the state, which is the main stimulator of economic interest in the implementation of environmental innovations. 


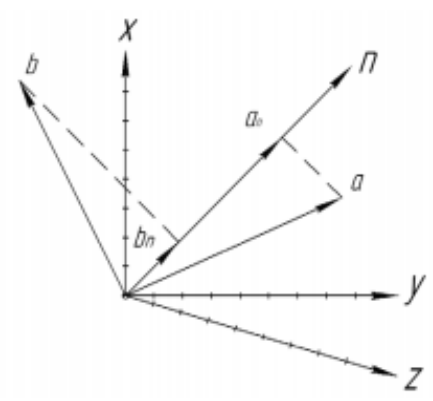

Fig. 2. Indicator of the innovative level of the project [4].

The proposed approach to the assessment assumes the equivalence of the results of the implementation of an innovative project, which does not allow us to speak of the universality of the proposed approach, at the same time, the role of the state as the main stakeholder in the implementation of environmental innovations is taken into account.

The team of authors L.M. Idigova, M.A. Dovletmurzaeva and B.Kh. Rakhimova, as a measure to increase the efficiency of the enterprise's innovative activities, propose to form an environmental management system based on the ISO 14001 standard, which, along with a quality management system based on the ISO 9001 and / or an occupational health and safety management system based on the OHSAS 18001 standard is included in an integrated management system. [5] The proposed integration, according to the authors, will provide a systematic decrease in production costs in connection with the optimization of technological processes; reduction of payments for negative impact on the environment and effective implementation of the requirements of environmental legislation; makes it possible to get additional benefits, such as:

- reducing the risks of emergencies;

- increasing competitiveness;

- the possibility of developing new markets;

- reduction of interest rates on loans;

- strengthening of investment attractiveness.

The proposed system is purely descriptive and it is not possible to analyze its effectiveness. At the same time, the system reflects the cyclical nature and has the potential for further research based on the outlined approaches.

Authors Kakava L.O and Likhachev E.M. note the shortcomings of existing models of innovative design of environmental innovations, such as:

- a strong cut in resources,

- dependence on the general political and economic situation,

- the need for highly qualified specialists,

- lack of working and effective communication with the scientific sector.

Most of the ongoing innovative projects in view of the current circumstances are focused on the short and medium term and do not take into account the strategic goals of the enterprise. [6] Proceeding from this, the authors have developed a model of innovative design of an ecological project, based on a combination of organizational, technological, information resource support. The most applicable for environmental innovation projects, according to the authors, are design models characterized by a multi-institutional, network nature. Also, in the design of eco-investments, the "Gate" model by Robert Cooper [7] is used, where the project is divided into a predetermined series of stages that are "crossfunctional" with a system of parallel actions from different functional structures. Before each stage, there are "gates" that serve to control the quality of the project, determine its priority, decide on the continuation / termination of the project and allocate the appropriate 
resources [8]. Most importantly, at each stage, it is possible to verify the compliance of environmental projects with the goals of the enterprise, but the inability to return projects to earlier stages reduces the effectiveness of the model. Based on the noted features of the development of models, the authors propose a model for innovative design of an ecological innovation project.

The authors highlight the environment in which an ecological innovation project is being implemented, which they differentiate into external and internal. In the external environment, the main influencing factors are ecology, economics, legislation, scientific and technological progress, consumers, suppliers, competitors, credit institutions and the information environment. The authors refer to internal factors: finance, technological features of production, organizational structure, investments in fixed assets and finished goods. For the successful implementation of an environmental project, the authors note the need to develop information, organizational and economic support for the project, as well as technologies and technical support. At the same time, solving an environmental problem should pay off and bring positive effects for the organization and contribute to the achievement of the organization's strategic goals.

The team of authors Belyakov G. Ya., Falaleev A. N. and Shishkina N. A. identify the main factors that have a direct impact on the quality of environmental innovation projects [9]. In the course of the study conducted by the authors, based on the study of global trends $[10,11]$, the following factors were proposed that affect the quality of environmental innovation projects:

- environmental: tightening of environmental standards in domestic and world practice; energy and environmental safety requirements; increasing the role of the population through public environmental expertise, etc .;

- technological: the need to achieve the best parameters in the field of energy and material consumption, labor productivity, the use of the latest information and telecommunication technologies;

- economic: ensuring competitiveness in the global and domestic markets; outstripping the level of added value in production.

The proposed classification of factors in the group of technological factors takes into account not only the achievements of scientific and technological progress, but also the latest trends in increasing the efficiency of resource use, which has a beneficial effect on the environment and the environmental load on the external environment. At the same time, the proposed groups of factors and the individual factors included in them are not differentiated in terms of the degree of influence on the implementation of an innovative project.

The most interesting method for managing innovative projects is the technology developed by Masloboev A.V. and Maximova V.V. [12] The method proposed by the authors for assessing the effectiveness of innovations at the initial stages of the life cycle, based on the use of the mathematical apparatus of the theory of fuzzy sets, is implemented within the information technology of complex analysis and assessment of the effectiveness of innovations and consists of the following stages:

1) Preliminary analysis of the innovation project

The purpose of this stage is to check the observance of intellectual property rights when a new innovative project appears (comparison with analogues, determination of the degree of difference and detection of plagiarism). At this stage, information technologies for data mining on innovative projects and automated information retrieval systems are implemented.

2) Screening out unpromising innovative projects

The purpose of the second stage is to exclude unpromising innovative projects from consideration. At this stage, methods for assessing the competence of innovators who put 
forward innovative projects are being implemented, as well as procedures for verifying the compliance of the declared innovative projects with the selection criteria.

3) Economic and mathematical analysis and fuzzy modeling of innovative projects

At this stage, the expertise of innovative projects is carried out. The purpose of this stage is to obtain qualitative and quantitative assessments of the effectiveness of innovative projects in the form of fuzzy computational models. On the basis of the estimates obtained, particular indicators of the effectiveness of innovations (social, scientific and technical, environmental, economic efficiency) are calculated.

4) Simulation and forecasting of the development of innovative projects

At this stage, methods of forecasting demand for innovative products are being implemented at the development stage in order to determine the market effect from the implementation and implementation of innovation.

5) Formation of many effective business projects that are promising for financing

The purpose of this stage is to form a set of effective innovative projects, ranked according to the degree of importance depending on the goals of innovation and the type of investor, taking into account the estimates obtained at the previous stages, as well as collecting and presenting detailed information about projects and their participants.

The method proposed by the authors provides an opportunity to analyze the effectiveness of both innovative ideas and detailed innovative projects, including a business plan and an approximate scheme for the implementation of the main stages of the project. At the same time, the authors do not take into account the environmental aspects of innovative projects at the final stages of the innovation life cycle, such as recycling and reuse.

The management of environmental innovation projects at the micro level is actively studied by foreign scientists, for example, Graciela González and Raúl Mar. They note that in the face of the economic and environmental crisis, companies need to implement innovative projects to improve their performance. Many companies adopt an innovationdriven environmental management policy and therefore seek international cooperation to grow their business faster. The authors investigated the possibility of creating a strategy for inter-firm interaction, the introduction of environmental innovations to improve the efficiency of organizations. [13]

A team of authors Renata Konadu, Samuel Owusu-Agyei, Theophilus Lartey, and others analyzed the relationship between CEO reputation and environmental innovation, seeing quality management as a mediator of these relationships. Moreover, the authors identified the constraining role of resource commitments in the relationship between quality management and environmental innovation. As a result, the authors found that when a firm commits itself to using resources for the implementation of quality management methods, the efficiency of quality management increases as one of the main means of implementing environmental innovations. [14]

Finally, a team of authors from Lviv Polytechnic University Mykola Odrekhivskyi, Uliana Kohut, Roman Kochan and others have developed an ecological innovation system based on an innovation process, which is aimed at accelerating the development of environmental innovations and solving complex issues of the global environmental situation (Fig. 3). 


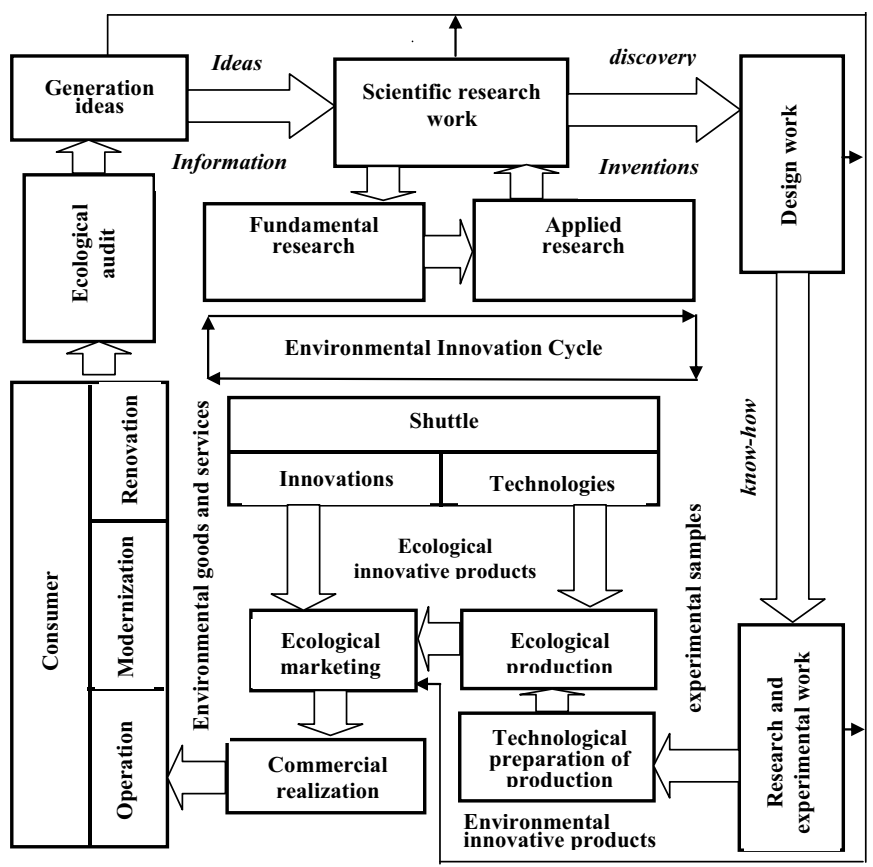

Fig. 3. Functional model of environmental innovation process [15].

The practical value of the work lies in the fact that the development of a global ecological innovation system at different levels (mega-, macro-, meso- and microlevels) of the hierarchy will facilitate the rapid generation, dissemination, implementation and use of environmental information. The process of environmental innovation, which is the basis for the implementation of the global system, will allow the environmental sphere to constantly be in horizontal and vertical (national, international, global) innovation cycles. All this will help solve complex environmental problems and improve the global environmental situation. [15]

Thus, as a result of an in-depth analysis of existing methods and approaches to the management of environmental innovation projects developed by domestic and foreign scientists, it is worth noting that they do not take into account the differentiation of the importance of influencing factors on an innovative project, while at the micro level, management activities are not considered throughout life. cycle for the implementation of the project. Finally, from the point of view of the concept of continuous improvement, the Deming cycle is not reflected as one of the important features in the development of a methodology for managing environmental innovation projects. In this regard, it is necessary to take into account the identified features and propose the author's methodology for managing environmental innovation projects.

\section{Results}

Based on the relevance of intensifying the implementation of environmental innovation projects at enterprises, a deep analysis of domestic and foreign methods and approaches to the management of environmental innovation projects was carried out. The methods discussed above indicate that the topic is important, and the development and improvement of the methodological apparatus is necessary to increase the efficiency of management of environmental innovation projects. At the same time, the considered methods do not take 
into account the differentiation of the importance of influencing factors on the innovative project, while at the micro level there is no management activity throughout the entire life cycle of the project. In this regard, it is necessary to take into account the identified features and propose the author's methodology for managing environmental innovation projects.

The development of the methodology will allow to formalize the sequence of actions for the subjects of management at the enterprise in order to select the most effective projects that contribute to the achievement of the strategic goals of the enterprise. The development of a methodology for managing environmental innovation projects consists of four main stages (Fig. 4).

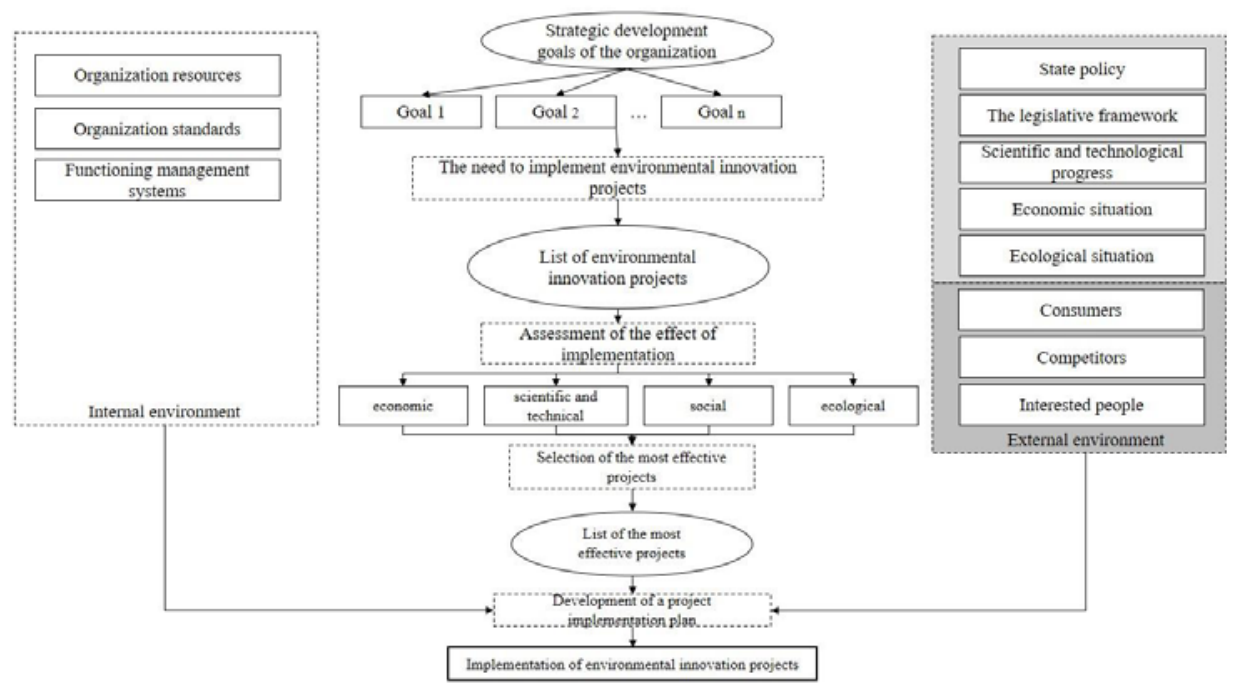

Fig. 4. Methodology for managing environmental innovation projects at the enterprise.

At the first stage, the strategic goals of the enterprise are determined. Currently, enterprises cannot develop in a highly competitive market without building a long-term development strategy. Therefore, it is extremely important to determine precisely the strategic, long-term goals based on external and internal factors affecting the organization's activities. Based on the strategic goals of the organization, it is possible to formulate the need for environmental innovation projects, the implementation of which will allow achieving the stated goals of the organization $[1,2]$.

The second stage consists in the formation of a list of environmental innovative developments that the organization either generates independently or searches for them on the market. More details about the generation of innovative developments were discussed earlier [16-19]. When forming the list of projects, it is necessary to take into account the development prospects, its potential for implementation at the enterprise, the impact on the environment, etc.

After the list of projects is formed, it is necessary to assess the projects for the effect of their implementation at the enterprise. The assessment should be carried out using mathematical methods, for example, using a fuzzy-multiple approach. The proposed method allows an objective assessment of innovative projects, forming fuzzy assessment intervals. The implementation of environmental innovation projects allows you to obtain four main effects: economic, scientific and technical, social and environmental. At the same time, it should be noted that when implementing innovative projects, an organization can get several effects. 
At the third stage, the most effective projects are selected. To carry out the selection of projects, it is necessary to calculate a complex indicator of the effect of the implementation of an ecological innovation project. We find the complex indicator as the sum of the products of the implementation effects and their weight coefficients. In this case, we can arrange the weight coefficients using Fishburne's law.

$$
E_{k 1}=\sum E i \cdot \vartheta_{i}
$$

Ei - the effects of the implementation of an environmental innovation project (economic, scientific and technical, social, environmental)

$\mathrm{v}$ is the weighting factor of the corresponding effect.

As a result, of the selection, we obtain a list of the most effective innovative projects for the $n$-th organization in the $n$-th period of time.

At the final fourth stage, a plan for the implementation of an environmental innovation project is formed, which takes into account both internal factors of the organization and external ones. The main internal factors of the organization will be:

- resources of the organization (financial, human, intellectual, technical, technological, organizational);

- standards of the organization, an internal documented base that ensures the effective work of the organization;

- the organization's management systems, for example, compliance with the ISO 9000 and 14000 series.

The combination of internal factors will have a significant impact on the implementation plan for an environmental innovation project, for example, for the duration of the project in terms of organizational, technical, documented, etc. preparation for the implementation of the project.

We differentiate external factors into two subgroups: factors that the organization does not have a significant impact on (government policy, legislative framework, scientific and technological progress, economic situation in the country / region, environmental situation in the region) and factors that the organization has a significant impact on (consumers, competitors, stakeholders).

In accordance with the formed implementation plan for the selected environmental innovation projects, the projects are being implemented at the enterprise.

Thus, the developed methodology allows you to formalize the sequence of actions for the subjects of management at the enterprise in order to select the most effective projects that contribute to the achievement of the strategic goals of the enterprise, taking into account external and internal factors.

\section{Discussion}

The developed methodology for managing environmental innovation projects requires a deeper study of methods for forming a list of environmental innovation projects, as well as assessing the effect of project implementation using mathematical modeling.

The list of environmental innovation projects can be formed due to the internal potential of the organization, i.e. develop a system for generating innovative projects. At the same time, it is necessary to develop a methodology for the selection of potentially more effective innovative projects for the organization.

The assessment of the effect of the implementation of innovative projects, as already proposed in the study, can be carried out using a fuzzy-multiple approach. 


\section{Conclusion}

Thus, an in-depth study of existing methods and approaches to the management of environmental innovation projects, developed by domestic and foreign scientists, was carried out. They do not take into account the differentiation of the importance of influencing factors on the innovative project, while at the micro level there is no management activity at all stages of the life cycle for the implementation of the project. In order to accumulate existing approaches and clarify the identified features, a methodology for managing environmental innovation projects was formed. The technique allows you to formalize the sequence of actions for the subjects of management at the enterprise in order to select the most effective projects that contribute to the achievement of the strategic goals of the enterprise, taking into account external and internal factors.

\section{References}

1. E.E. Abushova, S.N. Kyzmina, V.A. Leventsov and A.V. Chernikova, Economics and Entrepreneurship (2020)

2. A.V. Chernikova and Yu.I. Krylova, Digital technologies in the economy and industry, 706-713(2019)

3. A.A. Rogovoi, Bulletin of Eurasian Science 7 (2015)

4. E.I. Pavlova, Creative economy (2014)

5. L.M. Idigova, M.A. Dovletmurzaeva, and B.Kh. Rakhimova, Trends in the development of science and education (2020)

6. L.O. Kakava and E.M. Likhachev, Scientific journal of NRU ITMO. Series "Economics and Environmental Management" (2018)

7. R.G. Cooper, S.J. Edgett, E.J. Kleinschmidt, Res. Manag. 45, 43 (2002)

8. R.G. Cooper, Bus. Horiz. 33, 44 (1990)

9. G.Ya. Belyakova, A.N. Falaleev, and N.A. Shishkina, Siberian Journal of Science and Technology (2014)

10. M. Kerdeman, A. Rizzardi, World Bank (2009)

11. W.W. Lewis, The power of productivity: Wealth, poverty, and the threat to global stability (University of Chicago Press, 2005)

12. A.V. Masloboev and V.V. Maksimova, Proceedings of the Kola Scientific Center of the Russian Academy of Sciences (2010)

13. G.C. González, R.H. Mar, Rev. Sci. Gest. (2010)

14. R. Konadu, S. Owusu-Agyei, T. A. Lartey, A. Danso, S. Adomako, J. Amankwah-Amoah, Bus. Strateg. Environ. 29, 2310 (2020)

15. M. Odrekhivskyy, U. Kohut, R. Kochan, V. Karpinskyi, M. Bernas, 19th Int. Multidiscip. Sci. GeoConference SGEM 2019, 587-594 (2019)

16. N.N.Shevchenko and B.M. Lyamin, Scientific Review Theory and Practice 36 (2018)

17. A.B. Mottaeva, Lyamin, B.M., Economic sciences 191, 81 (2020)

18. B. Lyamin, V. Ulanov, T. Cherkasova, O. Milkova, IOP Conf. Ser. Mater. Sci. Eng. 940, $12072(2020)$

19. B. Lyamin, E. Konnikov, A. Furin, V. Kuzmenko, I. Andronov, в Proc. Int. Sci. Conf. Digit. Transform. Manuf. Infrastruct. Serv. (Association for Computing Machinery, New York, NY, USA, 2020) 